\title{
Thermal and Mechanical Properties of Nanoclay-Poly(acrylic acid) Gel Reinforced Polyethylene Terephthalate/Clay Nanocomposite*
}

\author{
Wasuthep Luecha ${ }^{\dagger}$ and Rathanawan Magaraphan
}

The Petroleum and Petrochemical College, Chulalongkorn University, Bangkok, Thailand

(Received 13 January 2014; Revised 21 January 2015; Accepted 16 February 2015; Published 21 March 2015)

\begin{abstract}
A polyethylene terephthalate (PET)-based nanocomposite was prepared by using nanoclay-polyacrylic acid gel (nanoclay-PAA gel) as a reinforcing filler. For nanoclay-PAA gel, the cation-exchange method was used to prepare an organoclay from bentonite clay and hexadecyl trimethylammonium chloride. The organoclay was then dispersed in isopropanol, mixed with PAA gel (PAA powder swollen in water at room temperature to $1 \mathrm{wt} \%$ ) under mechanical stirring, and neutralized with Triethanolamine (TEA). X-ray diffraction (XRD) showed an increasing of basal spacing and the intercalated structure of nanoclay gel was also found. The good distribution of organoclay in gel matrix were revealed with scanning electron microscope (SEM). PET/Clay nanocomposites with various inorganic clay contents $(1,2,3,4$ and $5 \mathrm{wt} \%)$, were then prepared via melt mixing in a twin screw extruder. PET/Clay nanocomposites structure, phase morphology, thermal and mechanical properties of PET/Clay nanocomposites were investigated by XRD, SEM, differential scanning calorimetry (DSC), Thermo gravimetric analyzer (TGA) and universal testing machine, respectively. The results reveals the exfoliated and intercalated structures of nanoclay in PET/Clay nanocomposites, the improvement of thermal properties and the increasing of crystallinity, leading to the enhancement of mechanical properties. [DOI: 10.1380/ejssnt.2015.107]
\end{abstract}

Keywords: Polyethylene terephthalate(PET); Poly(acrylic acid); Nanoclay gel; Nanocomposite; Organoclay

\section{INTRODUCTION}

Polymer/layered silicate nanocomposites-hybrid materials consisting of a polymer matrix reinforced with layered silicate nanoclay-have attracted noticeable scientific and technological interest due to the enhanceability of the material properties such as mechanical properties, thermal stability, flame retardancy and optical properties, in comparison to unfilled polymers or common micro composites [1]. Layered silicate nanoclays, e.g., montmorillonite and bentonite are widely used as reinforcing fillers because they are environmentally friendly, nontoxic, abundant in nature, and inexpensive [2]. Besides, a good dispersion of these fillers is the basic requirement to achieve the optimum reinforcement and the best property profile for Polymer/Clay nanocomposite. Surface modification of nanoclay is one of the most effective methods that is used to control aggregation and agglomeration of nanofiller particles, dispersion and filler-matrix interactions [3]. It can be achieved through ion exchange of interlayer cations with cationic quaternary ammonium salts, so called cation-exchange method, in order to convert hydrophilic nanoclay into hydrophobic organoclay [4].

Polyethylene terephthalate (PET), a semi-crystalline thermoplastic, is produced by a condensation reaction between dimethyl terephthalate or terephthalic acid and ethylene glycol. PET can be used in many applications such as textile fibers, carbonated beverage bottles, food and non-food containers, and engineering plastics in automobile manufacture $[5,6]$.

For polymer/clay nanocomposite, however, the dustcausing and the coagulating properties due to extremely small particle size and high specific surface area of nanoclay can pose significant problems during the melt mixing process. The nanoclay dust causes the air pollution affecting the human respiratory system while the coagulated nanoclay makes the polymer/layered silicate nanocomposites difficult to control their structure. To overcome these problems, a nanoclay gel is currently being studied. The nanoclay gel, nanoclay in gel form is prepared by dispersing nanoclay in polymer hydrogel such as polyacrylic acid (PAA). PAA is widely used as thickening and gelation agents due to crosslink structure [7].

On the basis of above consideration, the nanoclay gel was prepared from the organoclay and PAA. This nanoclay gel was then mixed with PET by melt blending in a twin screw extruder. The effect of nanoclay gel content on phase morphology, thermal and mechanical properties of PET/Clay nanocomposites has been investigated.

\section{EXPERIMENTAL}

\section{A. Materials}

Polyethylene terephthalate (PET) in a commercial grade (PET N1), with intrinsic viscosity of $0.8 \mathrm{dL} / \mathrm{g}$ and a melting point of $247^{\circ} \mathrm{C}$. was supplied by Indorama Polymer Public Company Limited. Bentonite clay was obtained from Thai Nippon chemical industry Co., Ltd. Poly acrylic acid (PAA) or AQUPEC HV-505HC was purchased from Sumitomo Seika Chemical Co., Ltd. in a white powder. Triethanolamine (TEA) and isopropyl alcohol were supplied by K.H. Co., LTD.

\section{B. Sample preparation}

\section{Nanoclay gel preparation}

The organoclay were obtained by modification of bentonite with hexadecyl trimethylammonium chloride 
$\left(\mathrm{C}_{19} \mathrm{H}_{42} \mathrm{~N}^{+} \mathrm{Cl}^{-}\right)$via cation-exchange method. After modification, isopropyl alcohol $(50 \mathrm{ml})$ was used to form a suspension of organoclay ( $3 \mathrm{~g}$ ) by sonicating for $30 \mathrm{~min}$ at room temperature (approximately $27^{\circ} \mathrm{C}$ ). Nanoclay gel was prepared by the following procedure. The suspension was added into $100 \mathrm{~g}$ of $1 \%$ aqueous solution of PAA. The mixtures were stirred vigorously at room temperature for $1 \mathrm{~h}$ and then TEA was added to neutralize the mixtures.

\section{PET/Clay nanocomposites preparation}

PET/Clay nanocomposites were prepared by melt extrusion process. Prior to mixing, PET and nanoclay gel with various ratios $(1,2,3,4$ and $5 \mathrm{wt} \%$ of inorganic contents with stoichiometric calculation) were mixed first with compound mixer and dried at $60^{\circ} \mathrm{C}$ under a vacuum for $24 \mathrm{~h}$, and then mixed together in the twin screw extruder (Lab tech) with a length diameter ratio of 40 . The temperature profiles of the extruder were maintained at $250,255,260,265,265,265,265,265,265$ and $265^{\circ} \mathrm{C}$ that order from hopper to die. The screw speed was set to 35 rpm.

\section{Characterization}

The X-ray diffraction (XRD) was used to investigate the basal spacing $(d)$ of the silicate nanolayers of bentonite, organoclay, nanoclay-gel, pristine PET and PET/Clay nanocomposites. The measurements were done by using a Bruker AXS X-ray diffractometer with $\mathrm{Cu} \mathrm{K}$ radiation $(\lambda=1.54056 \AA)$. The generator was operated at $40 \mathrm{kV}$ and $40 \mathrm{~mA}$. The spectra was recorded over a $2 \theta$ range of $2-10^{\circ}$ using a scan rate of $0.01^{\circ} / \mathrm{s}$.

The morphology of nanoclay gel and the cross-sectional surface of PET and PET/Clay nanocomposites were examined by using a scanning electron microscope (SEM; JSM-5900LV:JEOL) operated at $15 \mathrm{kV}$. All samples of pristine PET and PET/Clay nanocomposites were cryogenically broken after dipping in liquid nitrogen, and then coated by gold using JFC-1600 (JEOL) sputtering.

The thermal behavior and the crystallization parameters of the pristine PET and PET/Clay nanocomposites were studied by Differential scanning calorimeter (ParkinElmer DSC822) under $\mathrm{N}_{2}$ atmosphere to avoid any possible thermal degradation. The samples were heated from $25^{\circ} \mathrm{C}$ to $300^{\circ} \mathrm{C}$, held at $300^{\circ} \mathrm{C}$ for $5 \mathrm{~min}$, and then cooled to $25^{\circ} \mathrm{C}$ at the constant rate of $10^{\circ} \mathrm{C} / \mathrm{min}$.

The thermal stability of PET/Clay nanocomposites was examined by using a thermogravimetric analyzer (TGA Q-50) with the heating rate of $10^{\circ} \mathrm{C} / \mathrm{min}$ from $50^{\circ} \mathrm{C}$ to $800^{\circ} \mathrm{C}$ under nitrogen atmosphere. The percentage of weight loss was reported as a function of temperature.

The tensile properties, i.e., tensile strength, elongation at break and Young's modulus of pristine PET and PET/Clay nanocomposites were investigated by universal testing machine (Instron:H10KM) according to ASTM D638-08. The specimens were injected-molded into a dogbone shape. The tensile tests were carried out at room temperature. The crosshead speed was set at $10 \mathrm{~mm} / \mathrm{min}$. At least five specimens were used for each sample to determine an average and a standard deviation.

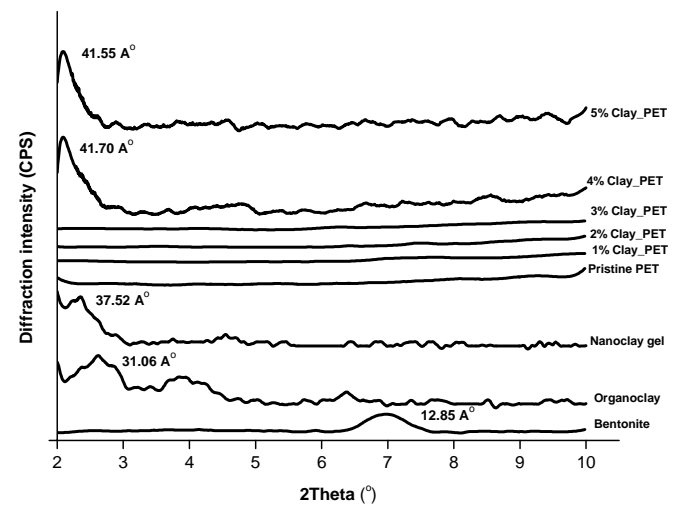

FIG. 1: XRD patterns of bentonite, organoclay, nanoclay-gel and PET/Clay nanocomposites.
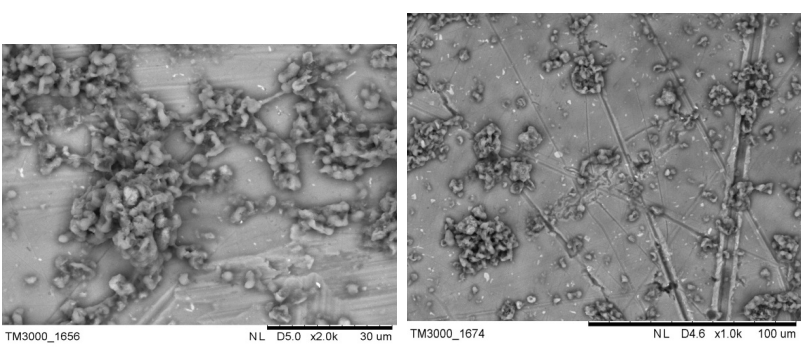

FIG. 2: Scanning electron micrographs of nanoclay gel.

\section{RESULTS AND DISCUSSIONS}

\section{A. The structure and morphology}

The XRD patterns of bentonite, organoclay, nanoclay gel and PET/Clay nanocomposites with various inorganic nanoclay contents are shown in Fig. 1.

Bentonite, organoclay and nanoclay gel showed the diffraction peaks at $2 \theta=6.88^{\circ}, 2.84^{\circ}$ and $2.35^{\circ}$, respectively. The calculated interlayer distance of bentonite was $12.85 \AA$ and shifted to $31.06 \AA$ for organoclay and $37.52 \AA$ for nanoclay gel. The increasing of $d$-spacing value is due to the presence of intercalated structure that is formed in the basal plane of silicate interlayers after surface modification and incorporation with PAA gel. The swelling of PAA chains has occurred in the silicate interlayers of nanoclay, providing the intercalated structure.

For XRD patterns of PET/Clay nanocomposites with clay contents of 1,2 and $3 \mathrm{wt} \%$, the results show the absence of basal plane peak and the formation of delamination revealing the exfoliated structure. It suggests that polymer molecules can penetrate into the silicate interlayers and induce the exfoliation of lamellar structure. At clay contents of 4 and $5 \mathrm{wt} \%$, however, XRD patterns of these PET/Clay nanocomposites demonstrated the intercalated structure due to the presence of the diffraction peak at $2 \theta=2.12^{\circ}$ and $2.13^{\circ}$, respectively.

SEM micrographs of nanoclay gel are shown in Fig. 2. The results show a good distribution of the nanoclay in PAA gel matrix. 

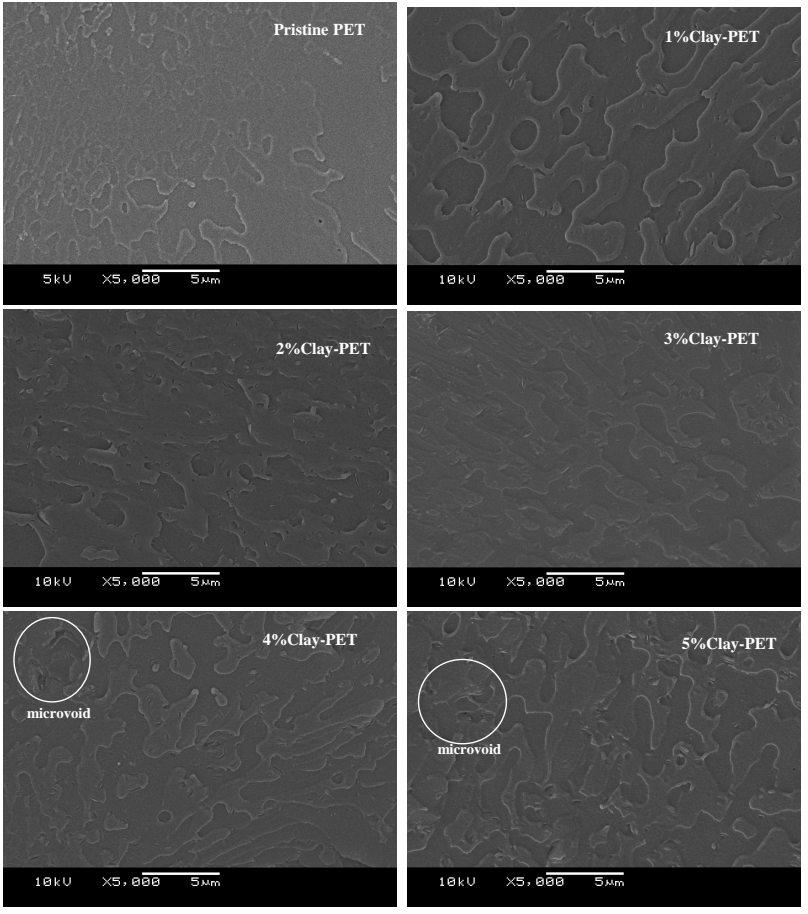

FIG. 3: Scanning electron micrographs of Pristine PET and $\mathrm{PET} /$ Clay nanocomposites with various inorganic nanoclay contents.

Figure 3 shows SEM micrographs of the cryofracture surfaces of the pristine PET and PET/Clay nanocomposites. A good dispersion of nanoclay particles in PET matrix is found in all samples. Besides, the results elucidated a good adhesion between clay and PET matrix due to the absence of void or crack at their interfaces. However, the observation found the microvoids in SEM micrographs of PET/Clay nanocomposites that a high amount of clay (4 and 5 wt $\%$ ) was added into the system.

\section{B. Thermal properties}

Table I shows the glass transition temperature $\left(\mathrm{T}_{\mathrm{g}}\right)$, the cold crystallization temperature $\left(\mathrm{T}_{\mathrm{cc}}\right)$, the melting temperature $\left(\mathrm{T}_{\mathrm{m}}\right)$, the crystallization temperature $\left(\mathrm{T}_{\mathrm{mc}}\right)$ and the crystallinity of pristine PET and PET/Clay nanocomposites with various clay contents. $\mathrm{T}_{\mathrm{g}}$ and $\mathrm{T}_{\mathrm{m}}$ of PET are around 76 and $250^{\circ} \mathrm{C}$, respectively, and addition of nanoclay into PET has no significant effect on these temperatures. However, $\mathrm{T}_{\mathrm{cc}}$ of PET/clay nanocomposites is lower than that of pristine PET. In general, the conformational arrangement of polymer chains from glassy to crystalline state is based entirely on the molecular reptation in the cold crystallization. Therefore, the cold crystallization of polymers often requires a certain amount of energy to overcome the potential barrier to the molecular segmental motion. This suggests that the segmental mobility of the organic modifiers and arrangements of PET chains between nanoclay layers became easier with the increasing temperature [8].

The clay particles in nanoscale act as an effective heterogeneous nucleating agent, and promote heterogeneous crystallization. It leads to the increasing of crystallinity
TABLE I: Thermal properties of pristine PET and PET/Clay nanocomposites with various inorganic nanoclay contents.

\begin{tabular}{cccccc}
\hline \hline Samples & $\begin{array}{c}\mathrm{T}_{\mathrm{g}} \\
\left({ }^{\circ} \mathrm{C}\right)\end{array}$ & $\begin{array}{c}\mathrm{T}_{\mathrm{cc}} \\
\left({ }^{\circ} \mathrm{C}\right)\end{array}$ & $\begin{array}{c}\mathrm{T}_{\mathrm{mc}} \\
\left({ }^{\circ} \mathrm{C}\right)\end{array}$ & $\begin{array}{c}\mathrm{T}_{\mathrm{m}} \\
\left({ }^{\circ} \mathrm{C}\right)\end{array}$ & $\begin{array}{c}\text { Crystalline Degree } \\
(\%)\end{array}$ \\
\hline Pristine PET & 76.31 & 123.61 & 200.26 & 250.00 & 22.48 \\
1\% Clay_PET & 77.86 & 121.55 & 202.11 & 250.32 & 31.87 \\
2\% Clay_PET & 79.32 & 120.97 & 203.25 & 250.62 & 32.55 \\
3\% Clay_PET & 79.98 & 119.88 & 204.31 & 251.16 & 33.93 \\
4\% Clay_PET & 77.02 & 122.22 & 202.56 & 250.03 & 31.44 \\
5\% Clay_PET & 76.40 & 123.14 & 201.45 & 249.97 & 29.57 \\
\hline \hline
\end{tabular}

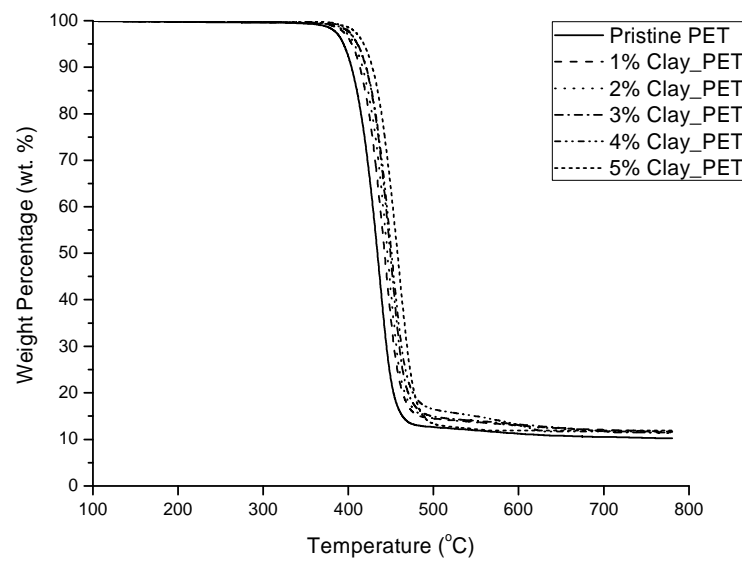

FIG. 4: TGA of pristine PET and PET/Clay nanocomposites with various inorganic nanoclay contents.

of PET/Clay nanocomposites compared to pristine PET. The crystallinity of PET/Clay nanocomposites show the highest value at $34 \%$ approximately for $3 \mathrm{wt} \%$ nanoclay content. $\mathrm{T}_{\mathrm{mc}}$ of PET/Clay nanocomposites is also found to increase due to the nucleation effect of nanoclay on PET matrix. In the molten state, the segments of PET molecules can easily interact with the surface of nanoclay, resulting in the development of crystallization nuclei [9$10]$.

Figure 4 shows TGA thermograms of pristine PET and PET/Clay nanocomposites with various clay contents. The results showed that the decomposition temperature at onset $\left(\mathrm{T}_{\mathrm{d} \text {,onset }}\right)$ of pristine PET was $409^{\circ} \mathrm{C}$ while $\mathrm{T}_{\mathrm{d} \text {,onset }}$ of PET/Clay nanocomposites at clay contents of $1-5$ wt $\%$ were $420,424,429,432$ and $434^{\circ} \mathrm{C}$, respectively. The more clay contents, the higher decomposition temperature of PET/Clay nanocomposites is revealed. As a consequence, the thermal stability of PET/Clay nanocomposites is improved because clay minerals represent some degree of flame retardant for polymers.

\section{Mechanical properties}

The tensile properties of pristine PET and PET/Clay nanocomposites with various clay contents are reported 

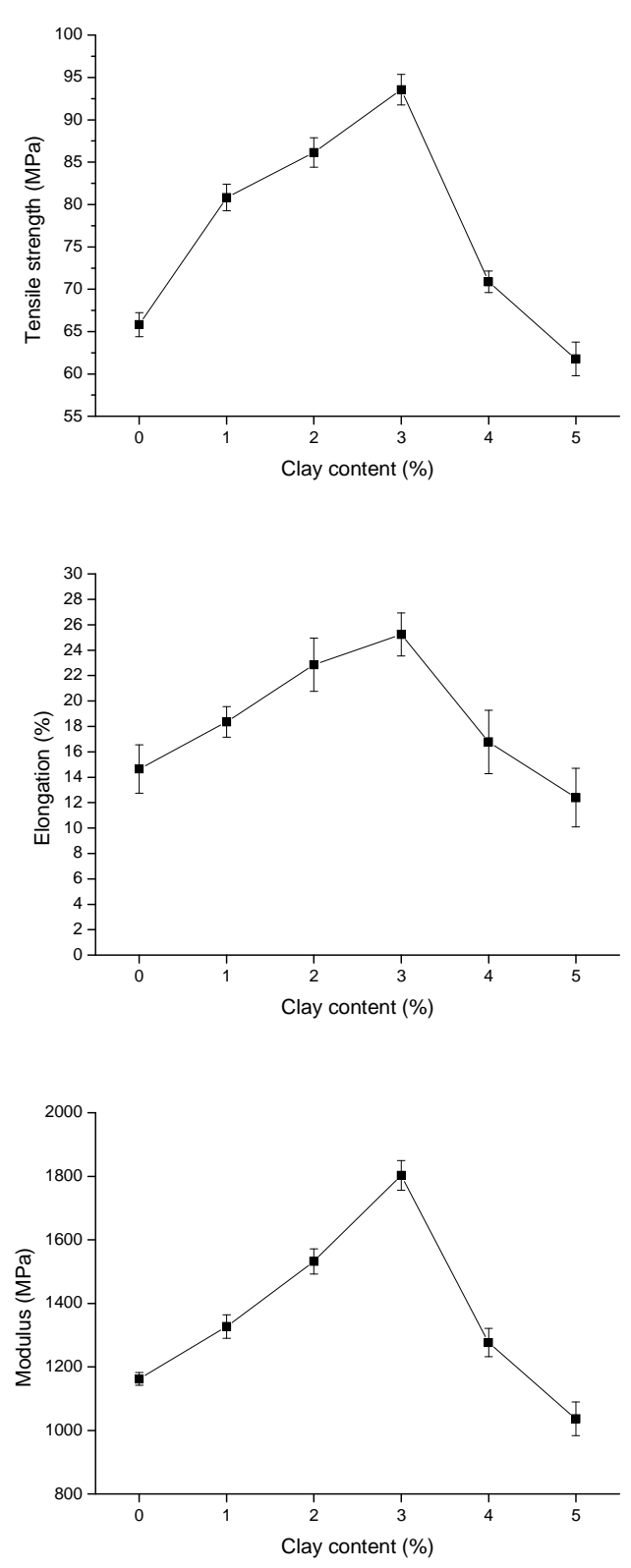

FIG. 5: Tensile strength, Elongation at break and Modulus of pristine PET and PET/Clay nanocomposites with various inorganic nanoclay contents.

in Fig. 5.
Compared to pristine PET, the tensile strength, elongation at break and modulus of PET/Clay nanocomposites dramatically increased with increasing clay content up to $3 \mathrm{wt} \%$. This is due to the exfoliated structure of silicate layer providing the optimum reinforcement. However, the tensile properties decreased when a high content (4-5 wt\%) of clay was added. This suggests that the clay partially remains the intercalated and stacked structure, causing the weakly reinforcing effect, the non-idealized nanoclay dispersion, and the presence of microvoids as shown in SEM micrographs. [11]

\section{CONCLUSION}

Nanoclay gel was prepared from organoclay and PAA. Nanoclay gel not only kept the expanded interlayer spacing of organoclay dispersed in PAA gel matrix, but also prevented the dust and the coagulation of nanoclay. The XRD pattern of nanoclay gel showed the intercalated structure while SEM micrographs revealed a good distribution of nanoclay particles in PAA gel matrix. The melt blending process was then used to prepare PET/Clay nanocomposites with clay contents of 1, 2, 3, 4 and $5 \mathrm{wt} \%$. XRD patterns of PET/Clay nanocomposites with various clay contents showed the exfoliated structures for 1-3 wt\% and the intercalated structure for 4-5 wt\%. A good dispersion of nanoclay in PET matrix was observed in SEM micrographs. The presence of nanoclay had no significant effected on $\mathrm{T}_{\mathrm{g}}$ and $\mathrm{T}_{\mathrm{m}}$ but it resulted in a decrease of $\mathrm{T}_{\mathrm{cc}}$ and an increased of $\mathrm{T}_{\mathrm{mc}}$ of PET with increasing clay content up to $3 \mathrm{wt} \%$. The thermal stability of PET/Clay nanocomposites was also improved with nanoclay loadings. The tensile properties of PET/Clay nanocomposites showed the highest values at the optimum clay content of $3 \mathrm{wt} \%$, corresponding to the increasing of $\mathrm{T}_{\mathrm{mc}}$ and crystallinity.

\section{Acknowledgments}

The author is thankful to The Higher Education Research Promotion and National Research University Project of Thailand, Office of the Higher Education Commission (CU56-FW07) and Integrated Innovation Academic Center: IIAC Chulalongkorn University Centenary Academic Development Project and The Petroleum and Petrochemical College, Chulalongkorn university.
[1] R. Gupta, E. Kennel, and K. Kim, Polymer Nanocomposites Handbook, 1st ed. (CRC Press, 2009).

[2] M. Alexandre and P. Dubois, Mat. Sci. Eng. 28, 1 (2000).

[3] Y. W. Mai and Z. Z. Yu, Polymer Nanocomposites (CRC Press, Woodhead, 2006).

[4] N. Mahadevaiah, B. Venkataramani, and B. S. J. Prakash, Chem. Mater. 19, 4606 (2007).

[5] S. Bhattacharya, R. Gupta, and M. Kamal, Polymeric nanocomposites: Theory and practice (Hanser Gardner Publications, 2007).

[6] D. Brooks and G. A. Giles, PET Packaging Technology, 1st ed. (Blackwell, 2002).

[7] H. Tabuteau, P. Coussot, and J. R. De-Bruyn, J. Rheol. 51, 125 (2007).

[8] A. Durmus, et al., Polym. Compos. 31, 1056 (2010).

[9] C. I. W. Calcagno, C. M. Mariani, and S. R. Teixeira, Polymer 48, 966 (2007).

[10] D. Salem, Structure Formation in Polymeric Fibers, 1st ed. (Hanser Gardner Publications, 2001).

[11] A. Pegorettia, J. Kolarikb, C. Peronia, and C. Migliaresia, Polymer 45, 2751 (2004). 